Aksiologiya: Jurnal Pengabdian Kepada Masyarakat

Vol.5, No. 2, Mei 2021 Hal 241 - 247

ISSN 2528-4967 (print) dan ISSN 2548-219X (online)

\title{
Kesediaan Membayar Terhadap Destinasi Wisata Omah Iwak Badher Bank
}

\author{
D.G.R. Wiadnya ${ }^{1}$, Sukandar ${ }^{2}$, A.P.W. Marhendra ${ }^{3}$, A.M. Hariati ${ }^{4}$, A. \\ Yuniarti $^{5}$, C.S.U. Dewi ${ }^{6}$, H. Nursyam ${ }^{7}$, C. Anam ${ }^{8}$, E.Y. Herawati ${ }^{9}$, Muammar \\ Kadhafi $^{10}$ \\ Universitas Brawijaya Malang \\ Email :dgr_wiadnya@ub.ac.id ${ }^{1}$, kdr_1212@ub.ac.id ${ }^{2}$, agung_pramana@ub.ac.id ${ }^{3}$, \\ a_hariati@ub.ac.id ${ }^{4}$, ating_y@ub.ac.id ${ }^{4}$, satryacitra@ub.ac.id ${ }^{5}$, happy_nsy@ub.ac. \\ id ${ }^{6}$, anam.imp76@gmail.com², herawati_ey@ub.ac.id ${ }^{7}$, \\ muammar_kadhafi@ub.ac.id ${ }^{2}$
}

\begin{abstract}
ABSTRAK
Omah Iwak Badher Bank ialah salah satu destinasi wisata di Kabupaten Blitar yang dikelola oleh POKMASWAS Fajar Bengawan. Penelusuran reviewer pada google.co.id mendapatkan total 77 orang pemberi ulasan dengan rata-rata rating 4.5 . Penelitian ini bertujuan untuk menilai rating destinasi terhadap responden terpilih, ialah mahasiswa S1 dan S3 Fakultas Perikanan dan Ilmu kelautan UB Malang. Total responden berjumlah 46 mahasiswa, 33 ialah mahasiswa S1 dan 13 mahasiswa S3. Kedua kelompok responden mendapat kesempatan yang sama untuk mengunjungi destinasi wisata. Rating dan penilaian terhadap destinasi dilakukan dengan memberikan 12 jenis pertanyaan kepada masing-masing resonden. Hasil penelitian mendapatkan bahwa rating responden mahasiswa S1 $(3,7 \pm 0,57)$ dan S3 $(3,7 \pm 0,48)$ lebih rendah dibandingkan dengan penilaian publik $(4,5)$. Hal ini menunjukkan kualitas destinasi yang menjadi perhatian mahasiswa lebih tinggi dibandingkan dengan umum. Kesediaan membayar mahasiswa S1 (Rp. 150.000 Trip-1) pada destinasi wisata relatif lebih rendah dibandingkan dengan mahasiswa S3 (Rp. 250.000 Trip-1). Sebagai destinasi wisata baru, Omah Iwak Badher Bank perlu melakukan peningkatan jasa untuk meningkatkan kualitas destinasi.
\end{abstract}

Kata Kunci: kesediaan membayar, jasa wisata, wisata alam, POKMASWAS

\section{Willingness-To-Pay To Omah Iwak Badher Bank Tourism Destination}

\begin{abstract}
Omah Iwak Badher Bank is one of the tourist destinations in Blitar Regency which is managed by POKMASWAS Fajar Bengawan. A reviewer search on google.co.id found a total of 77 reviewers with an average rating of 4.5. This study aimed to assess the destination rating of selected respondents, are undergraduate and doctoral students of the UB's Faculty of Fisheries and Marine Science Malang. The total respondents were 46 students, 33 were S1 students and 13 were S3 students. Both groups of respondents received the same opportunity to visit tourist destinations. Rating and assessment of destinations was done by giving 12 types of questions to each respondent. The results found that the average rating of undergraduate student respondents was $3.7 \pm 0.57$, and $3.7 \pm 0.48$ for S3 students, respectively. These were lower than that of public assessment (4.5). This indivated that the quality of destination that are of concern to students is higher than the public. Willingness-t-pay of undergraduate students (Rp. 150,000 Trip-1) at tourist destinations was relatifly lower compared to doctoral students (Rp. 250,000 Trip-1). As a new tourist destination, Omah Iwak Badher Bank needs to improve its services to improve the quality of the destination.
\end{abstract}

Keywords: willingness-to-pay, tourism services, nature tourism, POKMASWAS 
Dewa Gede Raka Wiadnya, Sukandar Sukandar, A.P.W Marhendra, Anik Martinah Hariati, Ating Yuniarti, Citra Satrya Utama Dewi, Happy Nursyam, C Anam, Endang Yuli Herawati, Muammar Kadhafi/Aksiologiya: Jurnal Pengabdian Kepada Masyarakat. Vol.5, No. 2, Mei 2021 Hal 241 - 247

\section{PENDAHULUAN}

Saat ini terdapat 391

Kelompok Pengawas Masyarakat (POKMASWAS) di Jawa Timur, didefinisikan sebagai sekumpulan orang yang peduli dengan kelestarian sumber daya ikan dan lingkungannya serta bekerja secara sukarela untuk melakukan pengawasan terhadap sumber daya tersebut (Yuliana, 2012). Ketentuan dasar keterlibatan masyarakat dalam pengelolaan dan pengawasan pemanfaaatan sumber daya ikan ialah sesuai dengan ketentuan Pasal 67 UU No. 31 Tahun 2004 tentang Perikanan (Suwarsono, 2018).

Selain sebagai relawan pengawas, POKMASWAS juga melakukan beberapa kegiatan rehabilitasi habitat maupun lingkungan di sekitar tempat tinggalnya (Harlyan, 2017), perlindungan spesies (Ratri, 2019), dan kegiatan lain terkait konservasi dan pemanfaatan sumber daya secara berkelanjutan. Hal ini biasa mereka lakukan tanpa atau dengan batuan dari pembina masyarakat pesisir(Nasution, 2018). Namun, sesuai dengan perjalanan waktu, tingkat partisipasi anggota kelomok berfluktuasi. Faktor utama ialah pada insentif terhadap anggota sebagai kompensasi dari curahan waktu dan tenaga mereka sebagai relawan (Susilo et.al, 2015). Jika anggota belum mapan secara ekonmi, tingkat partisipasi serta keberlanjutan program yang sudah dicanangkan sering tidak berlanjut (Viyanda, 2015).

Pemerintah bersama lembaga swadaya masyarakat lainnya sering melakukan pendampingan dalam kerangka pengembangan alternatif mata pencaharian yang lebih baik. Sebagai contoh, Pemerintah mengembangkan inisiatif untuk membantu pembuatan rumah ikan (Indrawati, 2017) yang tujuan utamanya untuk budidaya atau menampung hasil tangkapan. Tempat-tempat tersebut akhirnya menjadi tempat istirahat dan wisata bagi pengunjung. Akhir-akhir ini, ada kencendrungan POKMASWAS untuk mengembangkan jasa wisata sebagai salah satu bonus dari usaha konservasi mereka. Konservasi pada akhirnya akan menarik wisatawan untuk berkunjung dan berpartisipasi dalam usaha konservasi (Kiss, 2004). Fajar Bengawan ialah POKMASWAS yang mengusahakan perlindungan populasi ikan badher bank setelah mengalami penurunan akibat penangkapan tidak ramah lingkungan. Mereka melindungi $200 \mathrm{~m}$ badan sungai untuk tidak melakukan kegiatan ekstraktif. Selain itu, mereka mengusahakan agar ikan berkumpul dengan memberikan pakan sisa nasi rumah tangga ke dalam sungai. Setelah lebih dari dua tahun, populasi ikan badher bank mulai tampak pulih. Ikan yang datang di pinggir sungai menarik perhatian wisatawan. Perahu pengawas yang diberikan oleh pemerintah sering digunakan sebagai pelayanan wisata telusur sungai. Badher Bank akhirnya berkembang sebagai calon destinasi wisata dengan daya tarik melihat ikan makan, alam pedesaan dan telusur sungai. Penelitian dilakukan antara 
Dewa Gede Raka Wiadnya, Sukandar Sukandar, A.P.W Marhendra, Anik Martinah Hariati, Ating Yuniarti, Citra Satrya Utama Dewi, Happy Nursyam, C Anam, Endang Yuli Herawati, Muammar Kadhafi/Aksiologiya: Jurnal Pengabdian Kepada Masyarakat. Vol.5, No. 2, Mei 2021 Hal 241 - 247

bulan Juli - September 2019, dengan tujuan untuk menilai kesediaan membayar (WTP) dari wisatawan serta nilai rating dari destinasi wisata Omah Iwak Badher Bank.

\section{METODE PENELITIAN}

Sampai akhir bulan Juli 2019, destinasi wisata Omah Iwak Badher Bank telah diulas oleh 77 orang wisatawan dengan rata-rata nilai rating 4,5 (kisaran nilai 1 - 5) (http:// google.co.id). Pada akhir bulan Juli, sekelompok mahasiswa S1 FPIK-UB difasilitasiuntukmelakukankunjungan sehari ke Badher Bank. Selama kunjungan wisata, seluruh peserta (33 mahasiswa) mendapat kesempatan untuk berinteraksi dengan pengelola wisata (Fajar Bengawan). Seluruh mahasiswa mendapat penjelasan terkait dengan latar belakang, sejarah konservasi dan usaha kelompok untuk mengembangkan destinasi wisata. Pada bulan September, dengan metode yang sama, mahasiswa Pasca Sarjana (S3) FPIK-UB (13 mahasiswa) juga difasilitasi untuk berkunjung ke Badher Bank. Setelah kunjungan, setiap individu dari kedua kelompok diminta untuk membuat essay satu halaman terkait dengan pengalaman kunjungan wisata mereka. Dengan cara ini, setiap peserta (calon responden) diharapkan mempunyai persepsi yang sama terhadap destinasi wisata Badher Bank.

Setelah satu minggu, masingmasing peserta diminta mengisi kuisioner kesediaan membayar terhadap destinasi wisata yang mereka kunjungi. Form kesediaan membayar (WTP) tersusun atas 12 pertanyaan (Horowitz, 2003), terbagi atas: (a) kesediaan responden untuk membayar terhadap destinasi dan daya tarik wisata, (b) kelayakan Badher Bank sebagai destinasi wisata, (c) pelayanan pengelola, dan (d) nilai (rating) keseluruhan yang diberikan kepada destinasi yang mereka kunjungi. Responden mahasiswa S1 dianggap mewakili kelompok wisatawan muda kategori backpacker. Sedangkan mahasiswa S3 yang ratarata berumur $>40$ tahun dianggap bisa mewakili kelompok wisatawan dengan penghasilan relatif mapan (Jones, 2009).

Seluruh jawaban dari responden (46 mahasiswa) disusun dalam format database excel workbook. Penyajian data kesediaan membayar disajikan dalam bentuk Pie-Chart. Sedangkan perbandingan kesediaan membayar daya tarik wisata dari harga yang ditawarkan disajikan dalam bentuk table. Hasil analisis dibandingkan dengan ulasan yang diberikan oleh publik melalui http://google.co.id.

\section{HASIL DAN PEMBAHASAN Kesediaan Membayar}

Total biaya wisata yang bersedia dikeluarkan oleh mahasiswa S1 untuk berkunjung ke Badher Bank lebih rendah dibandingkan dengan mahasiswa S3, dengan nilai yang lebih beragam (Gambar 1). Sebagian besar (67\%) mahasiswa S1 hanya mau mengeluarkan uang IDR $<100.000$ untuk berkunjung ke Badher Bank. Sisanya (27\%) bersedia menghabiskan uang setara antara IDR 100.000250.000 per kunjungan. Sebaliknya, 
77\% mahasiswa S3 mau membayar IDR 100.000-250.000, dan sisanya (23\%) bahkan bersedia mengeluarkan uang antara IDR 250.000-500.000 per kunjungan

Penghasilan dan umur mempengaruhi segmen pasar terhadap destinasi wisata alam seperti Badher Bank (Zalatan, 1996). Mahasiswa S3 yang sudah berpenghasilan tetap dan berumur lebih matang, lebih menghargaidestinasialamdanbersedia mengeluarkan biaya yang lebih banyak untuk mendapatkan layanan wisata tersebut. Sebaliknya, kelompok umur dengan penghasilan yang belum mapan lebih memilih destinasi wisata murah dan menantang

Ketika ditawari untuk melakukan kunjungan ke lokasi wisata, masingmasingkelompokmemberikanrespons yang berbeda. Setelah mempelajari karakter destinasi wisata yang ditawarkan (Badher Bank), mahasiswa S3 menunjukkan ketertarikan yang lebih tinggi dibanding mahasiswa S1. Hal ini mereka tunjukkan dengan saling memberi informasi terkait destinasi yang akan dikunjungi.

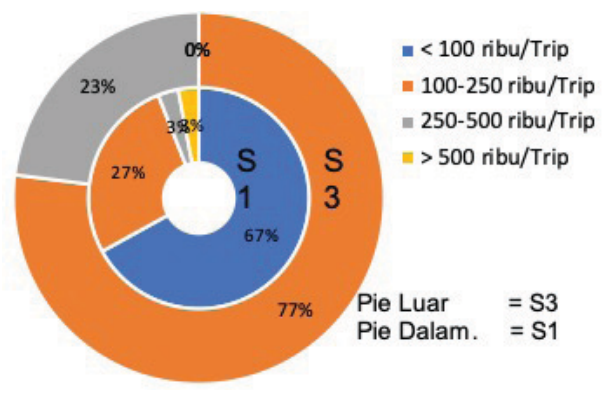

Gambar 1. Total maksimum uang yang bersedia dikeluarkan untuk membeli satu paket wisata ke Badher Bank (perbandingan mahasiswa S1 dan S3)
Hal yang sama tidak tampak pada mahasiswa S1. Bahkan sebagian dari mereka tidak datang walaupun dengan subsidi biaya transportasi dan makan siang.

Penawaran harga terhadap tiga daya tarik wisata (tiket masuk dikombinasi dengan memberi makan ikan, telusur sungai, dan dayung) mendapatkan bahwa mahasiswa S1 ingin membayar harga yang lebih rendah dari yang ditawarkan. Sebaliknya, mahasiswa S3 bahkan mau membayar harga yang lebih tinggi dari yang ditawarkan (Tabel 1).

Tingkat pendapatan merupakan salah satu faktor yang mempengaruhi kesediaan seorang wisatawan untuk membayar harga suatu unit daya tarik wisata (Zalatan, 1996). Namun umur yang lebih matang juga akan mempengaruhi dalam menentukan tingkat penghargaan terhadap alam. Wisatawan yang lebih tua biasanya mempunyai daya pengorbanan yang lebih tinggi dalam memilih kualitas daya tarik wisata yang berhubungan dengan alam. Oleh karena itu Fajar Bengawan sebaiknya lebih focus pada promosi terhadap wisatawan yang lebih berusia lanjut.

Data kunjungan mendapatkan bahwa Badher Bank lebih banyak menerima paket pertemuan dari kelompok wisatawan yang sudah mapan, seperti kelompok Dharma Wanita atau pegawai suatu institusi. Kelompok remaja umumnya memanfaatkan Badher Bank sebagai tempat untuk ngobrol dan hanya memilih paket wisata dengan harga minimal. 
Dewa Gede Raka Wiadnya, Sukandar Sukandar, A.P.W Marhendra, Anik Martinah Hariati, Ating Yuniarti, Citra Satrya Utama Dewi, Happy Nursyam, C Anam, Endang Yuli Herawati, Muammar Kadhafi/Aksiologiya: Jurnal Pengabdian Kepada Masyarakat. Vol.5, No. 2, Mei 2021 Hal 241 - 247

Tabel 1: Perbandingan antara mahasiswa S1 dan S3 terhadap kesediaan membayar dengan harga yang ditawarkan

\begin{tabular}{lcccc}
\multicolumn{5}{c}{ yang ditawarkan } \\
\hline Daya Tarik & \multicolumn{5}{c}{ HARGA PAKET } \\
\cline { 2 - 5 } Wisata (DTW) & $<$ & $<$ & $<$ & $<10 \mathrm{~K}$ \\
& $2,5 \mathrm{~K}$ & $5,0 \mathrm{~K}$ & $7,5 \mathrm{~K}$ & \\
\hline Tiket masuk: & $5,0 \mathrm{~K}$ \\
\hline Pilihan S1 & $3 \%$ & $27 \%$ & $30 \%$ & $29 \%$ \\
\hline Pilihan S3 & 0 & 0 & $31 \%$ & $69 \%$ \\
\hline Telusur sungai: & $50 \mathrm{~K}$ & & \\
\hline Pilihan S1 & $3 \%$ & $58 \%$ & $36 \%$ & $3 \%$ \\
\hline Pilihan S3 & \multicolumn{5}{c}{$31 \%$} & $54 \%$ & $15 \%$ \\
\hline Kano (dayung) & \multicolumn{5}{c}{$20 \mathrm{~K}$} \\
\hline Pilihan S1 & $30 \%$ & $67 \%$ & $3 \%$ \\
\hline Pilihan S3 & $8 \%$ & $92 \%$ \\
\hline Pelaynan
\end{tabular}

\section{Pelayanan Pengelola}

Sampai awal Juli 2019, destinasi wisata Badher Bank sudah diulas oleh 77 pengunjung wisata (http://google. co.id). Rata-rata rating yang diberikan oleh pengunjung mencapai 4,5 (dari nilai tertinggi $=5$ ). Responden mahasiswaS1 danS3 memberikannilai yang sama, masing-masing $3,7 \pm 0,57$

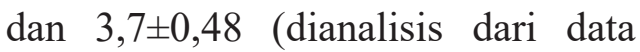
pada Tabel 2). Hal ini menunjukkan bahwa rating mahasiswa terhadap destinasi wisata Badher Bank lebih rendah dibandingkan dengan rata-rata publik

\section{Rating (ulasan) Responden}

\begin{tabular}{llr}
\multicolumn{1}{c}{ Perbedaan } & antara & ulasan \\
mahasiswa & dengan & publik \\
kemungkinan & disebabkan & oleh
\end{tabular}
perbedaan motivasi dan nilai riil pengeluaran terhadap destinasi wisata. Kunjungan responden ke destinasi Badher Bank ialah melalui permintaan peneliti. Selain itu, responden mendapat subsidi ketika berkunjung ke Badher Bank, dalam bentuk transportasi, minum, snack dan makan siang. Sebaliknya, publik secara riil sudah berkunjung ke destinasi Badher Bank melalui dana sendiri. Perbedaan ini mungkin menjadi penyebab utama rendahnya ulasan mahasiswa (Zalatan, 1996).

Tabel 2: Tingkat kepuasan responden (mahasiswa S1 dan S3) terhadap pelayanan pengelola dan ulasan terhadap destinasi wisata Badher Bank.

\begin{tabular}{lccccc}
\hline \multirow{2}{*}{ Parameter } & \multicolumn{5}{l}{$\begin{array}{l}\text { Skor (1 = sangat jelek; } 5= \\
\text { sangat baik) }\end{array}$} \\
\cline { 2 - 6 } & 1 & 2 & 3 & 4 & 5 \\
\hline Tingkat pelayanan pengelola (Fajar bengawan) \\
\hline Mahasiswa S1 & $0 \%$ & $0 \%$ & $12 \%$ & $55 \%$ & $33 \%$ \\
\hline Mahasiswa S3 & $0 \%$ & $0 \%$ & $15 \%$ & $39 \%$ & $46 \%$ \\
\hline Nilai (rating) destinasi wisata \\
\hline Mahasiswa S1 & $0 \%$ & $0 \%$ & $46 \%$ & $48 \%$ & $6 \%$ \\
\hline Mahasiswa S3 & $0 \%$ & $0 \%$ & $31 \%$ & $0 \%$ & $69 \%$ \\
\hline
\end{tabular}

Kedua jenis responden (S1 dan S3 FPIK-UB) mempunyai bekal cukup kuat terkait keaneka ragaman hayati, konservasi dan wisata alam. Omah Iwak Badher Bank mungkin masih dirasakan terlalu lokal untuk memberikandampakkonservasisecara global. Pada sisi lain, pemberian pakan ikan di sungai bisa saja berdampak negatif bagi kebersihan air sungai selain perubahan perilaku ikan. Hal ini diduga menjadi alasan lain bagi mahasiswa untuk memberikan ulasan yang lebih rendah

\section{SIMPULAN}

Rata-rata ulasan (rating) dari mahasiswa S1 dan S3 FPIK-UB terhadap destinasi wisata Badher Bank masing-masing ialah $(3,7 \pm 0,57)$ dan $(3,7 \pm 0,48)$. Nilai ini lebih rendah dibandingkan dengan rata-rata ulasan publik (77 pengunjung)yang mencapai 4,5. Seluruh responden mendapat subsidi dalam melakukan kunjungan 
dan inisiatif kunjungan berasal dari peneliti. Hal ini diduga sebagai penyebab utama rendahnya rating yang diberikan oleh mahasiswa.

Kesediaan membayar untuk satu paket wisata Badher Bank pada mahasiswa S1 lebih rendah dibandingkan dengan mahasiswa S3. Sekitar 67\% dari mahasiswa S1 hanya bersedia mengeluarkan biaya wisata $<$ Rp. 100.000 trip-1. Sisanya (27\%) bersedia mengeluarkan uang sampai Rp. $\quad 175.000$ Trip-1. Sebaliknya pada mahasiswa S3, sebanyak $77 \%$ menyatakan mau membayar Rp. 175.000 Trip-1. Sisanya (23\%) bahkan bersedia membayar > Rp. 250.000 Trip-1. Penghasilan yang lebih mapan, dikombinasi dengan umur diduga merupakan penyebab utama terjadinya perbedaan ini.

\section{UCAPAN TERIMA KASIH}

Penulis mengucapkan terima kasih kepada Program Doktor Mengabdi LPPM-UB dan FPIK-UB yang telah memfasilitasi pendanaan dari kegiatan di Badher Bank. Penulis juga mengucapkan terimakasih kepada mitra Fajar Bengawan yang telah bekerja keras dalam memajukan kelompok.

\section{DAFTAR PUSTAKA}

Harlyan, L. I., Sari, S. H. J., Yona, D. 2017. Fish Apartment as a Solution for Increasing Fish Catch in Pacitan Water, East Java. J. Innov. Appl. Technol., 3(1):376-380.

Horowitz, J. K, McConnell, K. E. 2003. Willingness to accept, willingness to pay and the income effect. J. Econ. Behav. Organ. 51(4):537-545.

Indrawati, I. 2017. Pengembangan community based tourism rumah apung Rembeng Raya pantai Mbangko'an sebagai wisata edukasi kelautan: pendampingan POKMASWAS dalam optimalisasi rumah apung Rembeng Raya pantai Mbangko'an di Dusun Karanggongso Desa Tasikmadu Kecamatan Watulimo. UIN Sunan Ampel Surabaya.

Jones, T, Wood, D, Catlin, J, Norman, B. 2009. Expenditure and ecotourism: predictors of expenditure for whale shark tour participants. J. Ecotourism. $8(1): 32-50$.

Kiss, A. 2004. Is community-based ecotourism a good use of biodiversity conservation funds?. Trends Ecol. Evol., 19(5):232-237.

Nasution, A. M., Wiranto, S, Madjid, A. 2018. Sinergi antara kelompokmasyarakatpengawas (POKMASWAS) dan pembinaan desa pesisir (BINDESIR) untuk membentuk satuan armada nelayan (SATARMANEL) dalam rangka mencegah ancaman keamanan maritim. Keamanan Maritim, 4(1):1-5.

Ratri, A. D. A. 2019. Peran kelompok masyarakat pengawas (POKMASWAS) dalam penyadaran konservasi penyu pantai Taman Kili-Kili (Studi di Dusun Bendogolor, Desa Wonocoyo, Kecamatan Panggul, Kabupaten Trenggalek). University of Muhammadiyah Malang.

Susilo, E, Purwanti, P, Lestariadi, R. A. 2015. Keberlanjutan 'Kejung Samudra' dalam pengelolaan dan pemanfaatan sumberdaya mangrove di Pancer Cengkrong dan Damas, Pantai Prigi, Trenggalek, J. Kebijak. Sos. Ekon. Kelaut. dan Perikan., 5(1):19-25.

Suwarsono, D. A. 2018. The Role of 
Dewa Gede Raka Wiadnya, Sukandar Sukandar, A.P.W Marhendra, Anik Martinah Hariati, Ating Yuniarti, Citra Satrya Utama Dewi, Happy Nursyam, C Anam, Endang Yuli Herawati, Muammar Kadhafi/Aksiologiya: Jurnal Pengabdian Kepada Masyarakat. Vol.5, No. 2, Mei 2021 Hal 241 - 247

Community-Based Surveillance (POKMASWAS) in Combating Illegal Fishing in Indonesia. Thesis, Flinders University, College of Science and Engineering.

Viyanda, F. T. 2015. Rencana Strategis Pengembangan Kelompok Masyarakat Pengawas Samudra Bakti Di Desa Bangsring Kecamatan Wongsorejo, Kabupaten Banyuwangi. Universitas Brawijaya.

Yuliana, E, Winata, A. 2012. Pengaruh Karakteristik Dan Persepsi Terhadap Tingkat Partisipasi Anggota Dalam Kelompok Masyarakat Pengawas (Pokmaswas). Sumber Daya Kelautan Dan perikanan. Bumi Lestari J. Environ, 12(2):1-5.

Zalatan, A, Ramirez, A, Gaston. 1996. Soft ecotourism: the substitution effect. Tour. Rev. 51(4): 42-48. 